\title{
Cytochrome P450 Epoxygenase-Dependent Activation of TRPV4 Channel Participates in Enhanced Serotonin-Induced Pulmonary Vasoconstriction in Chronic Hypoxic Pulmonary Hypertension
}

\author{
Yang Xia $\mathbb{D}^{1,}{ }^{1,2}$ Lexin Xia, ${ }^{1}$ Zhou Jin, ${ }^{1}$ Rui Jin, ${ }^{1}$ Omkar Paudel, ${ }^{2}$ and James S. K. Sham $\mathbb{D}^{2}$ \\ ${ }^{1}$ Department of Respiratory and Critical Care Medicine, Second Affiliated Hospital of Zhejiang University School of Medicine, \\ Hangzhou, Zhejiang 310009, China \\ ${ }^{2}$ Division of Pulmonary and Critical Care Medicine, Johns Hopkins School of Medicine, Baltimore, MD 21224, USA
}

Correspondence should be addressed to Yang Xia; yxia@zju.edu.cn and James S. K. Sham; jsks@jhmi.edu

Received 17 August 2019; Revised 10 December 2019; Accepted 28 December 2019; Published 22 January 2020

Academic Editor: Silvia Cantara

Copyright ( 2020 Yang Xia et al. This is an open access article distributed under the Creative Commons Attribution License, which permits unrestricted use, distribution, and reproduction in any medium, provided the original work is properly cited.

\begin{abstract}
Transient receptor potential vanilloid 4 (TRPV4) is a multi-functional non-selective channel expressed in pulmonary vasculatures. TRPV4 contributes to serotonin- (5-HT-) induced pulmonary vasoconstriction and is responsible in part for the enhanced 5-HT response in pulmonary arteries (PAs) of chronic hypoxia mice. Epoxyeicosatrienoic acid (EET) is an endogenous agonist of TRPV4 and is known to regulate vasoreactivity. The levels of EETs, the expression of cytochrome P450 (CYP) epoxygenase for EET production, and epoxide hydrolase for EET degradation are altered by chronic hypoxia. Here, we examined the role of EETdependent TRPV4 activation in the 5-HT-mediated PA contraction. In PAs of normoxic mice, inhibition of TRPV4 with a specific inhibitor HC-067047 caused a decrease in the sensitivity of 5-HT-induced PA contraction without affecting the maximal contractile response. Application of the cytochrome P450 epoxygenase inhibitor MS-PPOH had no effect on the vasoreactivity to 5-HT. In contrast, inhibition of CYP epoxygenase or TRPV4 both attenuated the 5-HT-elicited maximal contraction to a comparable level in PAs of chronic hypoxic mice. Moreover, the inhibitory effect of MS-PPOH on the 5-HT-induced contraction was obliterated in PAs of chronic hypoxic trpv $4^{-1-}$ mice. These results suggest that TRPV4 contributes to the enhanced 5-HT-induced vasoconstriction in chronic hypoxic PAs, in part via the CYP-EET-TRPV4 pathway. Our results further support the notion that manipulation of TRPV4 function may offer a novel therapeutic strategy for the treatment of hypoxia-related pulmonary hypertension.
\end{abstract}

\section{Introduction}

Chronic hypoxic pulmonary hypertension $(\mathrm{CHPH})$, which belongs to the Group 3 in the pulmonary hypertension classification [1], can be instigated by sustained exposure to hypoxia. Increasing evidence indicates that nonselective cation channels affect intrinsic changes in ionic balance and $\mathrm{Ca}^{2+}$ homeostasis in the pulmonary arterial smooth muscle cells and play pivotal roles in acute $[2,3]$ and prolonged hypoxic responses [4-7].

Transient receptor potential (TRP) channels are a set of nonselective cation channels containing seven protein families [8]. TRPV4, serving as an osmo-mechanosensitive channel, is widely expressed and functioning in both systemic and pulmonary vasculatures [9] and is gated by numerous stimuli including moderate heat, shear stress, osmotic, chemical stimuli, and the endogenous agonist, epoxyeicosatrienoic acids (EETs) [8, 10-18]. Cytochrome P450 (CYP) epoxygenases, especially CYP 2 group, metabolize membrane arachidonate to generate EETs [19]. In systematic vasculatures, EET-induced TRPV4 activation causes potent vasodilating effect [14]. Several mechanisms have been proposed: (1) activation of calcium-activated $\mathrm{K}^{+}$channels by the diffusion of endothelial-derived EETs to vascular smooth muscle [14]; (2) endothelial TRPV4 activation opens endothelial small and intermediate conductance $\mathrm{Ca}^{2+}$-activated $\mathrm{K}^{+}$channels, resulting in direct coupling of the endothelium and smooth muscle or the accumulation of $\mathrm{K}^{+}$in the extracellular space to hyperpolarize the smooth muscle [20]; and (3) TRPV4 coupled with ryanodine receptors and $\mathrm{BK}_{\mathrm{Ca}}$ channels to elicit 
smooth muscle hyperpolarization and arterial dilation via $\mathrm{Ca}^{2+}$-induced $\mathrm{Ca}^{2+}$ release in response to putative EETs [14, 15, 21-23].

In the lung, TRPV4 channels are distributed in human bronchial epithelial cells, airway smooth muscle cells, endothelial cells, and vascular smooth muscle cells in pulmonary arteries (PAs) [16]. They are involved in multiple physiological functions. TRPV4 is reported to play many different roles in the regulation of cell volume, vasomotor tone, endothelial mechanosensation, thermosensing, and vascular/epithelial permeability [13]. In contrast to the vasodilatory effect in systematic vasculatures, TRPV4, in pulmonary vasculature, contributes to vasoconstriction [24]. We have previously found that chronic hypoxia $(\mathrm{CH})$ upregulates the expression of TRPV4 in pulmonary arteries, which results in elevated myogenic tone, intracellular calcium $\left(\left[\mathrm{Ca}^{2+}\right]_{\mathrm{i}}\right)$, and vascular remodeling [25]. TRPV4 regulates serotonin- (5-HT-) induced $\mathrm{Ca}^{2+}$ response in normoxia $[24,26]$. More importantly, in chronic hypoxia, increased 5-HT-induced maximal contraction in PAs is partially reversed by TRPV4 antagonist [24]. In concordance, enhanced 5-HT-induced contraction is significantly reduced in PAs of hypoxic $\operatorname{trp} v 4^{-/-}$mice [24]. The development of hypoxia-induced pulmonary hypertension and pulmonary vascular remodeling is also delayed and suppressed in $\operatorname{trp} v 4^{-1-}$ mice [25]. On the other hand, chronic hypoxia upregulates CYP epoxygenases expression [27], downregulates the soluble epoxide hydrolase [28], increases the TRPV4 agonist EETs production, and facilitates the acute hypoxic pulmonary vasoconstriction (HPV) and chronic hypoxia-induced pulmonary vascular remodeling $[27,28]$. Moreover, blockage of soluble epoxide hydrolase enhances hypoxic pulmonary vasoconstriction, supporting the role of EETs in acute hypoxic response $[29,30]$. However, whether CYP-EET-TRPV4 signaling pathway is involved in 5-HT-elicited PA contraction in normal condition and in chronic hypoxia has not been studied. Hence, we hypothesize that CYP-EET regulates the agonistinduced vasoconstriction through TRPV4 activation in pulmonary hypertension. In the present study, we aim to test this hypothesis by using the currently available selective antagonists and $\operatorname{trp} v 4^{-1-}$ mice to probe the contribution of CYP-EET-TRPV4 in agonist-induced contraction in PAs of normal and $\mathrm{CHPH}$ mice.

\section{Materials and Methods}

2.1. Chronic Hypoxic Exposure. Male $\operatorname{trp} v 4^{-/-}$mice and wildtype (WT) mice were age-matched (C57BL/6J; 8 weeks old). The mice are kind gifts from Dr. Wolfgang Liedtke's lab, Duke University. The generation of $\operatorname{trp} v 4^{-1-}$ mice have been previously described [31]. The mice were placed in a hypoxic chamber and exposed to hypoxia $\left(10 \% \mathrm{O}_{2}\right)$ for 3-4 weeks to induce hypoxic pulmonary hypertension as described previously [24]. Control mice were housed in the same condition but exposed to room air.

2.2. Isolation and Isometric Tension Measurement of PAs. The mice pulmonary arteries were isolated, cut into segments, de-endothelialized by gentle rubbing of the lumen with a moose hair, and placed in Krebs solution which contains the following (in $\mathrm{mM}$ ): $118 \mathrm{NaCl}, 4.7 \mathrm{KCl}, 0.57 \mathrm{MgSO}_{4}$, $1.18 \mathrm{KH}_{2} \mathrm{PO}_{4}, 25 \mathrm{NaHCO}_{3}, 10$ dextrose, and $1.25 \mathrm{CaCl}_{2}$ as previously described $[6,24]$. PA rings were then fixed on a wire myograph chamber with two stainless steel wires, filling with $16 \% \mathrm{O}_{2}$ plus $5 \% \mathrm{CO}_{2}$ gassed modified Krebs solution. Isometric tension development was recorded. The resting tension was set at the levels equivalent to $15 \mathrm{mmHg}$ or $25 \mathrm{mmHg}$ for normoxic and hypoxic mice, respectively. After a 60 -minute equilibration, $\mathrm{PA}$ rings were exposed to $60 \mathrm{mM}$ $\mathrm{KCl}$ to establish maximum contraction and to phenylephrine (PE, $1 \mu \mathrm{M})$ followed by ACh $(10 \mu \mathrm{M})$ to verify disruption of endothelium. The active tension induced by TRPV4 agonist was normalized to maximum contraction generated by $60 \mathrm{mM} \mathrm{KCl}$.

2.3. Chemicals and Drugs. HC-067047, 5-HT, MS-PPOH, and other chemicals were purchased from Sigma Chemical (St. Louis, MO). Stock solutions of HC-067047 and MS$\mathrm{PPOH}$ were prepared in DMSO and diluted $1: 1,000$ in $2 \mathrm{mM} \mathrm{Ca}^{2+}$-Tyrode solution.

2.4. Statistical Analysis. All data in the article are represented as means \pm SE. Three-parameter logistic model was applied for concentration-response curves as preciously described [24] (equation (1)), where $R$ stands for the normalized developed tension, $E_{\max }$ stands for the maximal response, $\mathrm{EC}_{50}$ stands for the effective concentration for $50 \%$ response, and $b$ stands for the slope factor.

$$
R=\frac{E_{\max }}{1+\left([A] / \mathrm{EC}_{50}\right)^{b}} .
$$

Statistical significance $(P<0.05)$ of the changes was compared with paired or unpaired Student's $t$ tests or by one- or two-way ANOVA with Bonferroni's post hoc test, wherever applicable.

\section{Results}

3.1. The Effect of HC-067047 and MS-PPOH in 5-HT-Induced $P A$ Constriction in Normoxia. To evaluate the contribution of EETs and the downstream TRPV4 in 5-HT-elicited PA constriction in normoxia, vascular tension was measured by wire myograph in the absence or presence of the CYP epoxygenase inhibitor MS-PPOH and the TRPV4 inhibitor HC-067047. Application of MS-PPOH caused no significant change of $E_{\max }$ (Figure 1(b)) or $\mathrm{EC}_{50}$ (Figure 1(c)) in PAs of normoxic WT mice. Consistent with our previous finding [24], inhibition of TRPV4 with HC-067047 had no effect on $\mathrm{E}_{\max }$ (Figure 1(b), $n=6$ ), but it caused a right shift of the concentration-response curve (control: $7.780 \pm 0.1134$ vs. HC-067047: $7.425 \pm 0.0884, P<0.05)$, suggesting a decrease in sensitivity to 5-HT after TRPV4 inhibition. These results demonstrate that in normoxia, CYP expoxygenasedependent EETs are not involved in 5-HT-induced PA contraction, while TRPV4 exhibits modest effect on 5-HTgenerated PA constriction. 


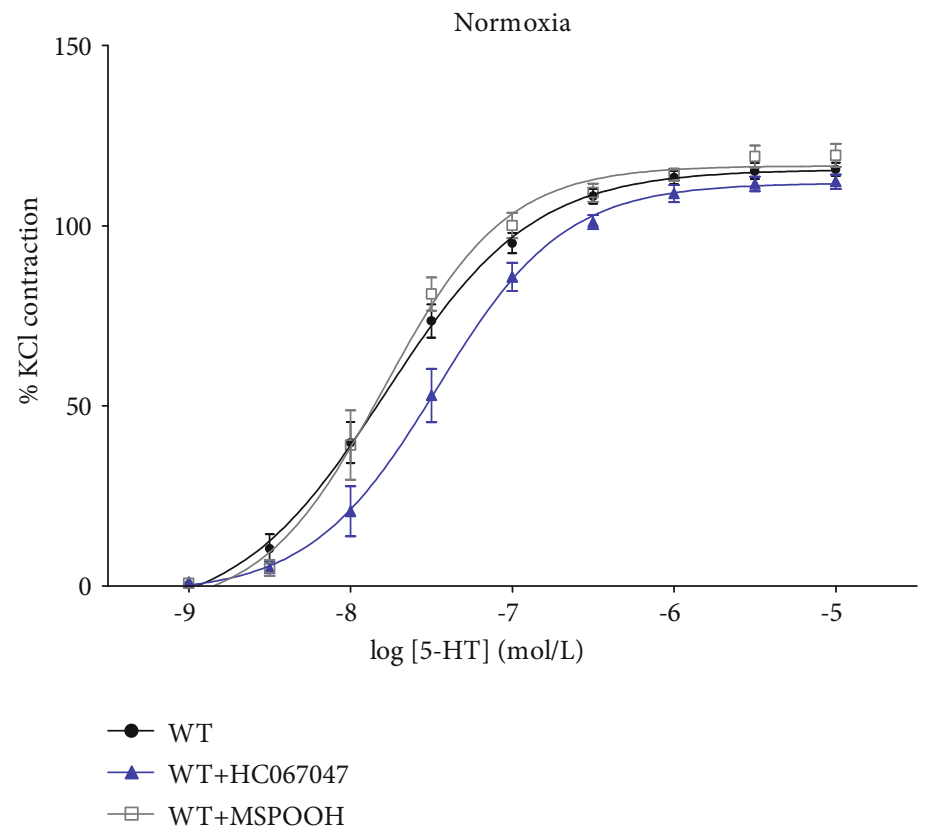

(a)

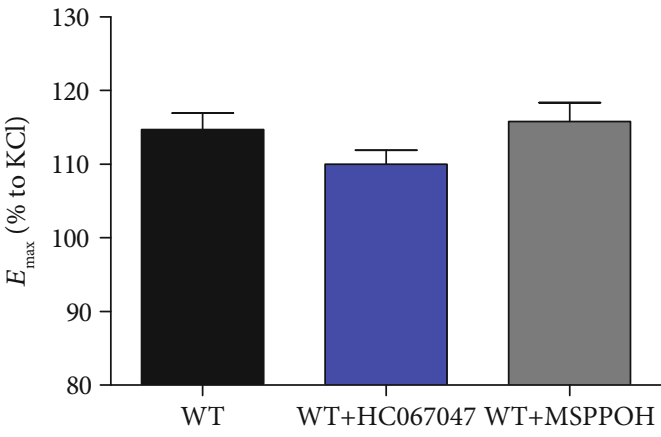

(b)

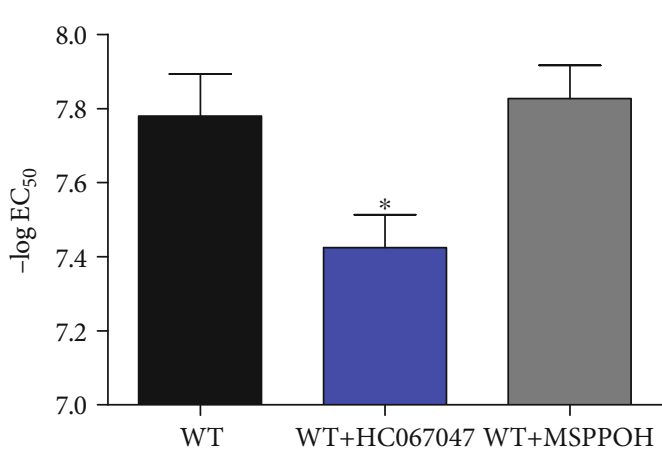

(c)

FIgURE 1: The effect of HC-067047 and MS-PPOH in normoxic WT mice. (a) Cumulative concentration-response curve of 5-HT, in PAs of WT mice with vehicle, MS-PPOH preincubation, and with HC-067047 preincubation, respectively. Data are expressed as a percentage of $\mathrm{K}^{+}$-induced contractile responses $(60 \mathrm{mM})$. (b, c) Bar graph showing the contractile response of normoxic PAs of WT mice, WT mice with HC-067047 preincubation and WT mice with MS-PPOH preincubation to serotonin. Mean values of maximal response ( $\left.E_{\max }\right)$ and $-\log \mathrm{EC}_{50}$ is derived from experiments shown in (a). $\mathrm{EC}_{50}$ and $E_{\max }$ were calculated from each individual PA using the 3-parameter logistic equation described in Materials and Methods. ${ }^{*} P<0.05$.

\subsection{Contribution of CYP-EET-TRPV4 in 5-HT-Induced PA} Constriction in Chronic Hypoxia. Consistent with previous findings, 5-HT-induced PA contraction was significantly potentiated in endothelium-denuded CH PAs $(n=10)$ compared to normoxic PAs $\left(E_{\max }: 178.1 \pm 9.767 \%\right.$ vs. $113.2 \pm$ $1.833 \%, P<0.01)$. Significant suppression of the enhanced 5 -HT response was observed after CYP epoxygenase inhibitor, MS-PPOH treatment $(n=6, P<0.05)$, and the inhibitory effect was similar to PAs treated with TRPV4 blocker, HC067047 ( $n=6$, nonsignificant). Moreover, 5-HT-activated maximum contractile response in genetic deletion of trpv4 $(n=10)$ was identical to that activated in WT PAs after TRPV4 inhibition $\left(\operatorname{trpv} 4^{-/-} E_{\max }: 153.4 \pm 6.207 \%\right.$ vs. WT+ HC-067047: $142.5 \pm 4.603 \%$, Figure 2(a)). Blockage of CYP epoxygenase inhibitor showed no effect on neither $E_{\max }$ nor $\mathrm{EC}_{50}$ in trpv4 null mice $(n=6$, Figures 2(b) and 2(c)).
In extension, we further evaluated the percentage increase in maximal response to 5-HT. Basically, $\mathrm{CH}$ caused $55 \%$ increase in maximum response to serotonin (Figure 2(d)). Of note, the percent enhancement was dramatically attenuated in HC-067047-treated and MS-PPOH-treated PAs of $\mathrm{CH}$ WT mice. Moreover, the $E_{\max }$ (HC-067047: $24.24 \pm$ $4.013 \%$ vs. MS-PPOH: $35.16 \pm 3.336 \%, P>0.05)$ and $-\log$ $\mathrm{EC}_{50}$ (HC-067047: $7.436 \pm 0.1673$ vs. MS-PPOH: $7.311 \pm$ $0.07788, P>0.05)$ of 5-HT-induced contractions were comparable in PAs of $\mathrm{CH}$ mice treated with HC-067047 and MS-PPOH. Most importantly, MS-PPOH did not caused additional inhibition in 5-HT induced PA constriction in $\mathrm{CH} \operatorname{trpv} 4^{-1-}$ mice (Figure 2(a)), indicating that the MS$\mathrm{PPOH}$-dependent inhibitory effect on 5-HT-induced contraction in $\mathrm{CH}$ WT mice was mediated specifically through the TRPV4 pathway. Collectively, these results 
Chronic hypoxia
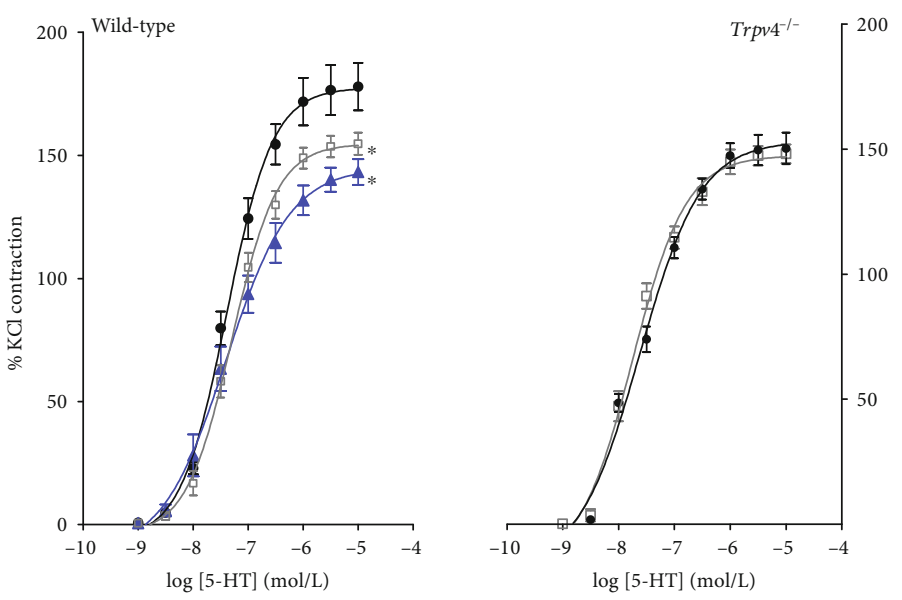

- Control

\ HC067047

$\square \mathrm{MSPPOH}$

(a)

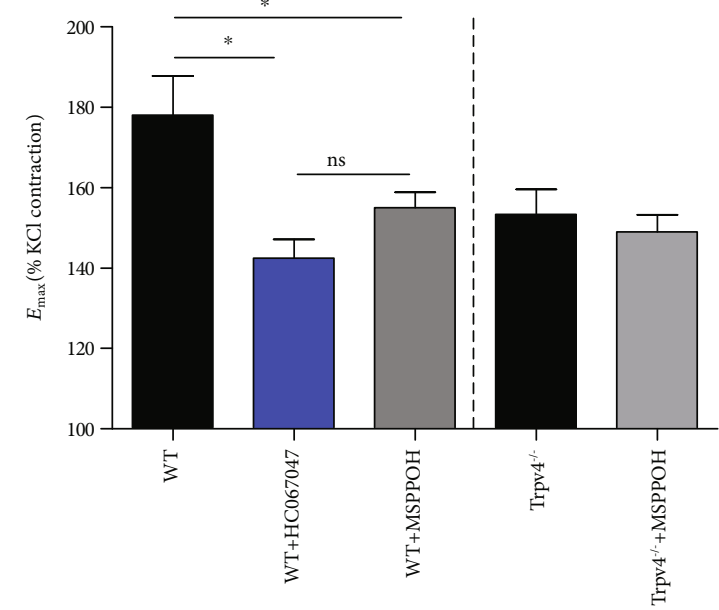

(b)

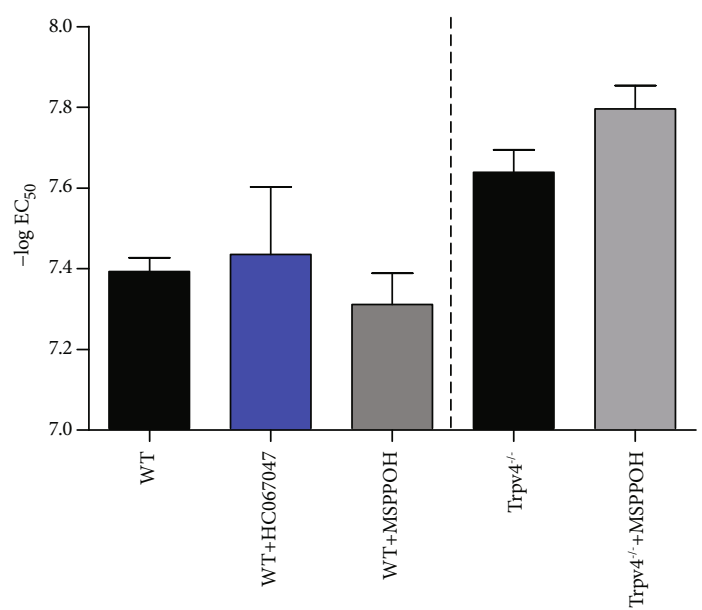

(c)

FIgURe 2: Continued. 


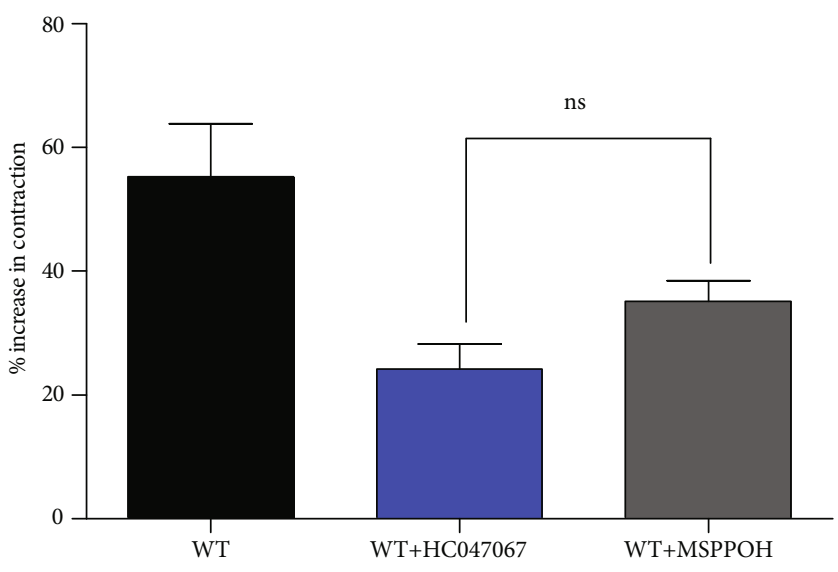

(d)

FIGURE 2: The effect of HC-067047 and MS-PPOH in WT and trpv4 $4^{-1-}$ mice in chronic hypoxia. (a) Cumulative concentration-response curve of 5-HT in PAs of WT mice and trpv4 $4^{-1-}$ mice with MS-PPOH preincubation and HC-067047 preincubation. Data are expressed as a percentage of $\mathrm{K}^{+}$-induced contractile responses $(60 \mathrm{mM})$. (b, c) Bar graph showing the contractile response of hypoxic PAs of WT mice and $\operatorname{trp} v 4^{-1-}$ mice to serotonin with $\mathrm{HC}-067047$ or MS-PPOH preincubation. Mean values of maximal response $\left(E_{\max }\right)$ and $-\log \mathrm{EC}_{50}$ is derived from experiments shown in (a). $\mathrm{EC}_{50}$ and $E_{\max }$ were calculated from each individual PA using the 3-parameter logistic equation described in Materials and Methods. (d) Bar graph showing percent inhibition of $\mathrm{K}^{+}$-induced contraction by HC-067047 and MS-PPOH in WT mice. ${ }^{*} P<0.05$; ns: nonsignificant.

clearly suggest that CYP-EET-TRPV4 is involved in the enhanced 5-HT-induced PA contraction in $\mathrm{CH}$.

\section{Discussion}

Enhanced vasoreactivity is a fundamental pathogenic mechanism for CHPH. In present study, we used pharmacological tools and trpv4 gene-deleted mouse models to test the hypothesis that the CYP-EET-TRPV4 pathway regulates the agonist-induced vasoconstriction in pulmonary hypertension. The major findings are as following: (1) in normoxia, inhibition of TRPV4 with a specific inhibitor HC-067047 caused a decrease in the sensitivity of 5-HT-induced PA contraction, as consistent with previous reports [24], while CYP epoxygenase inhibitor MS-PPOH did not affect vasoreactivity to 5-HT; (2) in chronic hypoxia, blockage of CYP epoxygenase or TRPV4 both attenuated 5-HT-elicited PA contraction to a similar level. More importantly, the inhibitory effect of MS$\mathrm{PPOH}$ on 5-HT induced PA contraction was is not observed in $\operatorname{trpv4^{-1-}}$ mice PA. These results suggest that the CYP-EETTRPV4 pathway is associated with 5-HT-dependent pharmacomechanical coupling in pulmonary hypertension.

A wealth of data shows that 5-HT plays a critical role in the hypoxia-induced pulmonary hypertension. Pulmonary hypertension is associated with increased plasma 5-HT [32], upregulated 5-HT1B and 5-HT2B receptors [33-35] and 5-HT transporter [36-38], and enhanced 5-HT-induced pulmonary vasoconstriction $[33,36,39-41]$. The involvement of CYP-EET-TRPV4 pathway in the enhanced 5-HTinduced vasoconstriction in $\mathrm{CH}$ pulmonary hypertension is supported by several lines of evidence. First, 5-HT has implication for the activation of TRPV4 in PASMCs. It has been shown that 5-HT activates ion current and $\mathrm{Ca}^{2+}$ influx which resemble TRPV4 activation in PASMCs; and the serotoninactivated current and $\mathrm{Ca}^{2+}$ signal could be inhibited by
TRPV4 inhibitors and the CYP epoxygenase inhibitor 17ODYA [42]. Second, TRPV4 expression is increased in PASMCs of $\mathrm{CH}$ rats $[5,25]$ providing an enhanced $\mathrm{Ca}^{2+}$ influx pathways for pulmonary vasoconstriction. Third, EETs metabolized from arachidonic acid (AA) by CYP epoxygenase are important endogenous agonists for TRPV4 activation [43]. Hypoxia exposure causes an increase of CYP expression and a resultant excessive production of endogenous EETs in the lung tissues was in line observed [27] and decreased the expression of soluble epoxide hydrolase, attenuating the metabolism of EETs into the inactive form [28] Fourth, 5-HT is known to regulate CYP enzymes' expression to cause an increase in CYP1A1 expression in the intestinal epithelial cells and CYP1B1 expression in PASMCs via the serotonin transporters [44-46]. Hence, it is most likely that part or all of the components on CYP-EET-TRPV4-serotonin pathway contribute to the enhanced vasoreactivity in the PAs of $\mathrm{CH}$ animals, including 5-HT receptor upregulation, the increased CYP epoxygenase expression and EET production, and the upregulation of TRPV4 expression. This is consistent with our present observations that CYP-EETTRPV4 pathway only has minimal effect on 5-HT-induced vasoconstriction in normoxic endothelium-free PAs. By contrast, the CYP-EET-TRPV4 pathway exhibits a significant influence in the elevated vasoreactivity in chronic hypoxia. Collectively, our observations vividly portray the pivotal role of the CYP-EET-TRPV4 pathway in the regulation of pulmonary vascular functions.

It has to be pointed that the enhanced pulmonary vasoconstriction is not completely inhibited by HC-067047 or MS-PPOH, because there are signaling mechanisms and channels, other than TRPV4, are participating in the 5-HTinduced pulmonary vasoconstriction. We have previously shown that TRPC6 is critically involved in 5-HT-generated contractile responses in PA under $\mathrm{CH}$, and TRPC1 also 
contributes in part to the enhanced vasoreactivity to 5-HT in $\mathrm{CH}$ [6]. Moreover, other channels including TRPV1 [47], voltage-gated $\mathrm{K}+$ channels [48], and calcium-activated chloride channel $[49,50]$ also participate in 5 -HT-induced pulmonary vasoconstriction.

There are several limitations of our study. First, our results only reflect observations in male animals, and gender differences have not been determined. It has been shown that hyperpolarization induced by EETs in systemic arteries is more pronounced in female than in male, and the effect of sex in CYP epoxygenase-related vasoresponses is crucial. Second, our study here focuses specifically on the functional aspect of pulmonary vascular reactivity to examine our hypothesis of the participation of the CYP-EETTRPV4 signaling pathway in the enhanced 5-HT-induced response in PA of chronic hypoxic mice. Future studies of additional cellular and molecular biology experiments are needed to provide a complete evaluation of this interesting observation of change in the modality of 5-HT-mediated signaling transduction.

Our present results clearly identified the differential role of CYP-EET-TRPV4 pathway in 5-HT-induced PA contraction under normoxic condition and $\mathrm{CHPH}$ and provide the supportive evidence that EETs participate in 5-HT-induced pulmonary vasoconstriction via the activation of TRPV4 channels in chronic hypoxia. Of note, the physiological and pathological roles of CYP-EET-TRPV4 pathways in PA remodeling and PASMC proliferation and migration in $\mathrm{CHPH}$ remain important for further investigation. Targeting TRPV4 may offer a novel therapeutic strategy for the treatment of hypoxia-related pulmonary hypertension.

\section{Data Availability}

The data used to support the findings of this study are included within the article.

\section{Conflicts of Interest}

The authors have declared no conflicts of interest.

\section{Acknowledgments}

This work was supported by the Zhejiang Provincial Natural Science Foundation of China [LY20H010004], the National Natural Science Foundation of China [81870022], and the Medical and Health Technology Program of Zhejiang Province [2017204226].

\section{References}

[1] G. Simonneau, D. Montani, D. S. Celermajer et al., "Haemodynamic definitions and updated clinical classification of pulmonary hypertension," The European Respiratory Journal, vol. 53, no. 1, p. 1801913, 2019.

[2] N. Weissmann, A. Dietrich, B. Fuchs et al., "Classical transient receptor potential channel 6 (TRPC6) is essential for hypoxic pulmonary vasoconstriction and alveolar gas exchange," Proceedings of the National Academy of Sciences, vol. 103, no. 50, pp. 19093-19098, 2006.
[3] W. Lu, J. Wang, G. Peng, L. A. Shimoda, and J. T. Sylvester, "Knockdown of stromal interaction molecule 1 attenuates store-operated $\mathrm{Ca}^{2+}$ entry and $\mathrm{Ca}^{2+}$ responses to acute hypoxia in pulmonary arterial smooth muscle," American Journal of Physiology. Lung Cellular and Molecular Physiology, vol. 297, no. 1, pp. L17-L25, 2009.

[4] M.-J. Lin, G. P. H. Leung, W.-M. Zhang et al., "Chronic hypoxia-induced upregulation of store-operated and receptoroperated $\mathrm{Ca}^{2+}$ channels in pulmonary arterial smooth muscle cells: a novel mechanism of hypoxic pulmonary hypertension," Circulation Research, vol. 95, no. 5, pp. 496-505, 2004.

[5] D. Dahan, T. Ducret, J. F. Quignard, R. Marthan, J. P. Savineau, and E. Estève, "Implication of the ryanodine receptor in TRPV4-induced calcium response in pulmonary arterial smooth muscle cells from normoxic and chronically hypoxic rats," American Journal of Physiology. Lung Cellular and Molecular Physiology, vol. 303, no. 9, pp. L824-L833, 2012.

[6] Y. Xia, X. R. Yang, Z. Fu et al., "Classical transient receptor potential 1 and 6 contribute to hypoxic pulmonary hypertension through differential regulation of pulmonary vascular functions," Hypertension, vol. 63, no. 1, pp. 173-180, 2014.

[7] M. Malczyk, C. Veith, B. Fuchs et al., "Classical transient receptor potential channel 1 in hypoxia-induced pulmonary hypertension," American Journal of Respiratory and Critical Care Medicine, vol. 188, no. 12, pp. 1451-1459, 2013.

[8] M. G. Belvisi and M. A. Birrell, "The emerging role of transient receptor potential channels in chronic lung disease," The European Respiratory Journal, vol. 50, no. 2, p. 1601357, 2017.

[9] Y. Xia, L. Xia, L. Lou, R. Jin, H. Shen, and W. Li, “Transient receptor potential channels and chronic airway inflammatory diseases: a comprehensive review," Lung, vol. 196, no. 5, pp. 505-516, 2018.

[10] J. M. Fernández-Fernández, Y. N. Andrade, M. Arniges et al., "Functional coupling of TRPV4 cationic channel and large conductance, calcium-dependent potassium channel in human bronchial epithelial cell lines," Pflügers Archiv - European Journal of Physiology, vol. 457, no. 1, pp. 149-159, 2008.

[11] Y. Jia, X. Wang, L. Varty et al., "Functional TRPV4 channels are expressed in human airway smooth muscle cells," American Journal of Physiology. Lung Cellular and Molecular Physiology, vol. 287, no. 2, pp. L272-L278, 2004.

[12] G. A. Fontana, F. Lavorini, and M. Pistolesi, "Water aerosols and cough," Pulmonary Pharmacology \& Therapeutics, vol. 15, no. 3, pp. 205-211, 2002.

[13] W. Everaerts, B. Nilius, and G. Owsianik, "The vanilloid transient receptor potential channel TRPV4: from structure to disease," Progress in Biophysics and Molecular Biology, vol. 103, no. 1, pp. 2-17, 2010.

[14] S. Earley, T. Pauyo, R. Drapp, M. J. Tavares, W. Liedtke, and J. E. Brayden, "TRPV4-dependent dilation of peripheral resistance arteries influences arterial pressure," American Journal of Physiology. Heart and Circulatory Physiology, vol. 297, no. 3, pp. H1096-H1102, 2009.

[15] R. Köhler, W.-T. Heyken, P. Heinau et al., "Evidence for a functional role of endothelial transient receptor potential V4 in shear stress-induced vasodilatation," Arteriosclerosis, Thrombosis, and Vascular Biology, vol. 26, no. 7, pp. 14951502, 2006.

[16] X.-R. Yang, M.-J. Lin, L. S. McIntosh, and J. S. K. Sham, "Functional expression of transient receptor potential melastatinand vanilloid-related channels in pulmonary arterial and aortic smooth muscle," American Journal of Physiology. Lung 
Cellular and Molecular Physiology, vol. 290, no. 6, pp. L1267L1276, 2006.

[17] J. Vriens, G. Owsianik, B. Fisslthaler et al., "Modulation of the $\mathrm{Ca}^{2}$ permeable cation channel TRPV4 by cytochrome $\mathrm{P} 450$ epoxygenases in vascular endothelium," Circulation Research, vol. 97, no. 9, pp. 908-915, 2005.

[18] H. Watanabe, J. B. Davis, D. Smart et al., "Activation of TRPV4 channels (hVRL-2/mTRP12) by phorbol derivatives," The Journal of Biological Chemistry, vol. 277, no. 16, pp. 1356913577, 2002.

[19] U. R. Michaelis and I. Fleming, "From endothelium-derived hyperpolarizing factor (EDHF) to angiogenesis: Epoxyeicosatrienoic acids (EETs) and cell signaling," Pharmacology \& Therapeutics, vol. 111, no. 3, pp. 584-595, 2006.

[20] G. J. Crane, N. Gallagher, K. A. Dora, and C. J. Garland, "Small- and intermediate-conductance calcium-activated $\mathrm{K}^{+}$ channels provide different facets of endothelium-dependent hyperpolarization in rat mesenteric artery," The Journal of Physiology, vol. 553, no. 1, pp. 183-189, 2003.

[21] D. X. Zhang, S. A. Mendoza, A. H. Bubolz et al., "Transient receptor potential vanilloid type 4-deficient mice exhibit impaired endothelium-dependent relaxation induced by acetylcholine in vitro and in vivo," Hypertension, vol. 53, no. 3, pp. 532-538, 2009.

[22] V. Hartmannsgruber, W. T. Heyken, M. Kacik et al., "Arterial response to shear stress critically depends on endothelial TRPV4 expression," PLoS One, vol. 2, no. 9, article e827, 2007.

[23] S. Earley, "Endothelium-dependent cerebral artery dilation mediated by transient receptor potential and Ca2+-activated K+ channels," Journal of Cardiovascular Pharmacology, vol. 57, no. 2, pp. 148-153, 2011.

[24] Y. Xia, Z. Fu, J. Hu et al., "TRPV4 channel contributes to serotonin-induced pulmonary vasoconstriction and the enhanced vascular reactivity in chronic hypoxic pulmonary hypertension," American Journal of Physiology. Cell Physiology, vol. 305, no. 7, pp. C704-C715, 2013.

[25] X.-R. Yang, A. H. Y. Lin, J. M. Hughes et al., "Upregulation of osmo-mechanosensitive TRPV4 channel facilitates chronic hypoxia-induced myogenic tone and pulmonary hypertension," American Journal of Physiology. Lung Cellular and Molecular Physiology, vol. 302, no. 6, pp. L555-L568, 2012.

[26] X.-R. Yang, M.-J. Lin, and J. S. K. Sham, "Physiological functions of transient receptor potential channels in pulmonary arterial smooth muscle cells," in Advances in Experimental Medicine and Biology, vol. 661, pp. 109-122, Humana Press, Totowa, NJ, 2010.

[27] P. Pokreisz, I. Fleming, L. Kiss et al., "Cytochrome P450 epoxygenase gene function in hypoxic pulmonary vasoconstriction and pulmonary vascular remodeling," Hypertension, vol. 47, no. 4, pp. 762-770, 2006.

[28] B. Keserü, E. Barbosa-Sicard, R. T. Schermuly et al., "Hypoxiainduced pulmonary hypertension: comparison of soluble epoxide hydrolase deletion vs. inhibition," Cardiovascular Research, vol. 85, no. 1, pp. 232-240, 2010.

[29] S. Kandhi, B. Zhang, G. Froogh et al., "EETs promote hypoxic pulmonary vasoconstriction via constrictor prostanoids," American Journal of Physiology. Lung Cellular and Molecular Physiology, vol. 313, no. 2, pp. L350-L359, 2017.

[30] M. Wepler, A. Beloiartsev, M. D. Buswell et al., "Soluble epoxide hydrolase deficiency or inhibition enhances murine hypoxic pulmonary vasoconstriction after lipopolysaccharide challenge," American Journal of Physiology. Lung Cellular and Molecular Physiology, vol. 311, no. 6, pp. L1213-L1221, 2016.

[31] W. Liedtke and J. M. Friedman, "Abnormal osmotic regulation in $\operatorname{trpv} 4^{-1-}$ mice," Proceedings of the National Academy of Sciences, vol. 100, no. 23, pp. 13698-13703, 2003.

[32] P. Hervé, J.-M. Launay, M.-L. Scrobohaci et al., "Increased plasma serotonin in primary pulmonary hypertension," The American Journal of Medicine, vol. 99, no. 3, pp. 249-254, 1995.

[33] A. Keegan, I. Morecroft, D. Smillie, M. N. Hicks, and M. R. MacLean, "Contribution of the $5-\mathrm{HT}_{1 \mathrm{~B}}$ receptor to hypoxiainduced pulmonary hypertension," Circulation Research, vol. 89, no. 12, pp. 1231-1239, 2001.

[34] J.-M. Launay, P. Hervé, K. Peoc'h et al., "Function of the serotonin 5-hydroxytryptamine $2 \mathrm{~B}$ receptor in pulmonary hypertension," Nature Medicine, vol. 8, no. 10, pp. 1129-1135, 2002.

[35] B. Rondelet, R. Van Beneden, F. Kerbaul et al., "Expression of the serotonin $1 \mathrm{~b}$ receptor in experimental pulmonary hypertension," The European Respiratory Journal, vol. 22, no. 3, pp. 408-412, 2003.

[36] S. Eddahibi, V. Fabre, C. Boni et al., "Induction of serotonin transporter by hypoxia in pulmonary vascular smooth muscle cells. Relationship with the mitogenic action of serotonin," Circulation Research, vol. 84, no. 3, pp. 329-336, 1999.

[37] S. Eddahibi, N. Hanoun, L. Lanfumey et al., "Attenuated hypoxic pulmonary hypertension in mice lacking the 5hydroxytryptamine transporter gene," The Journal of Clinical Investigation, vol. 105, no. 11, pp. 1555-1562, 2000.

[38] S. Eddahibi, M. Humbert, E. Fadel et al., "Serotonin transporter overexpression is responsible for pulmonary artery smooth muscle hyperplasia in primary pulmonary hypertension," The Journal of Clinical Investigation, vol. 108, no. 8, pp. 1141-1150, 2001.

[39] J. M. Esteve, J. M. Launay, O. Kellermann, and L. Maroteaux, "Functions of serotonin in hypoxic pulmonary vascular remodeling," Cell Biochemistry and Biophysics, vol. 47, no. 1, pp. 33-43, 2007.

[40] M. R. MacLean and I. Morecroft, "Increased contractile response to 5-hydroxytryptamine1-receptor stimulation in pulmonary arteries from chronic hypoxic rats: role of pharmacological synergy," British Journal of Pharmacology, vol. 134, no. 3, pp. 614-620, 2001.

[41] M. R. MacLean, G. Sweeney, M. Baird, K. M. McCulloch, M. Houslay, and I. Morecroft, "5-Hydroxytryptamine receptors mediating vasoconstriction in pulmonary arteries from control and pulmonary hypertensive rats," British Journal of Pharmacology, vol. 119, no. 5, pp. 917-930, 1996.

[42] T. Ducret, C. Guibert, R. Marthan, and J. P. Savineau, "Serotonin-induced activation of TRPV4-like current in rat intrapulmonary arterial smooth muscle cells," Cell Calcium, vol. 43, no. 4, pp. 315-323, 2008.

[43] P. K. Randhawa and A. S. Jaggi, "TRPV4 channels: physiological and pathological role in cardiovascular system," Basic Research in Cardiology, vol. 110, no. 6, p. 54, 2015.

[44] K. White, L. Loughlin, Z. Maqbool et al., "Serotonin transporter, sex, and hypoxia: microarray analysis in the pulmonary arteries of mice identifies genes with relevance to human PAH," Physiological Genomics, vol. 43, no. 8, pp. $417-437,2011$. 
[45] A. K. Z. Johansen, A. Dean, I. Morecroft et al., "The serotonin transporter promotes a pathological estrogen metabolic pathway in pulmonary hypertension via cytochrome P450 1B1," Pulmonary Circulation, vol. 6, no. 1, pp. 82-92, 2016.

[46] C. Manzella, M. Singhal, W. A. Alrefai, S. Saksena, P. K. Dudeja, and R. K. Gill, "Serotonin is an endogenous regulator of intestinal CYP1A1 via AhR," Scientific Reports, vol. 8, no. 1, p. 6103, 2018.

[47] T. Parpaite, G. Cardouat, M. Mauroux et al., "Effect of hypoxia on TRPV1 and TRPV4 channels in rat pulmonary arterial smooth muscle cells," Pflügers Archiv - European Journal of Physiology, vol. 468, no. 1, pp. 111-130, 2016.

[48] A. Cogolludo, L. Moreno, F. Lodi et al., "Serotonin inhibits voltage-gated $\mathrm{K}^{+}$currents in pulmonary artery smooth muscle cells: role of 5-HT2A receptors, caveolin-1, and KV1.5 channel internalization," Circulation Research, vol. 98, no. 7, pp. 931938, 2006.

[49] A. S. Forrest, T. C. Joyce, M. L. Huebner et al., "Increased TMEM16A-encoded calcium-activated chloride channel activity is associated with pulmonary hypertension," American Journal of Physiology. Cell Physiology, vol. 303, no. 12, pp. C1229-C1243, 2012.

[50] H. Sun, Y. Xia, O. Paudel, X. R. Yang, and J. S. K. Sham, "Chronic hypoxia-induced upregulation of $\mathrm{Ca}^{2+}$-activated $\mathrm{Cl}^{-}$channel in pulmonary arterial myocytes: a mechanism contributing to enhanced vasoreactivity," The Journal of Physiology, vol. 590, no. 15, pp. 3507-3521, 2012. 


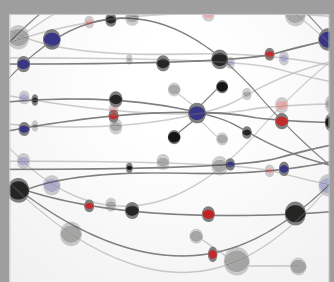

The Scientific World Journal
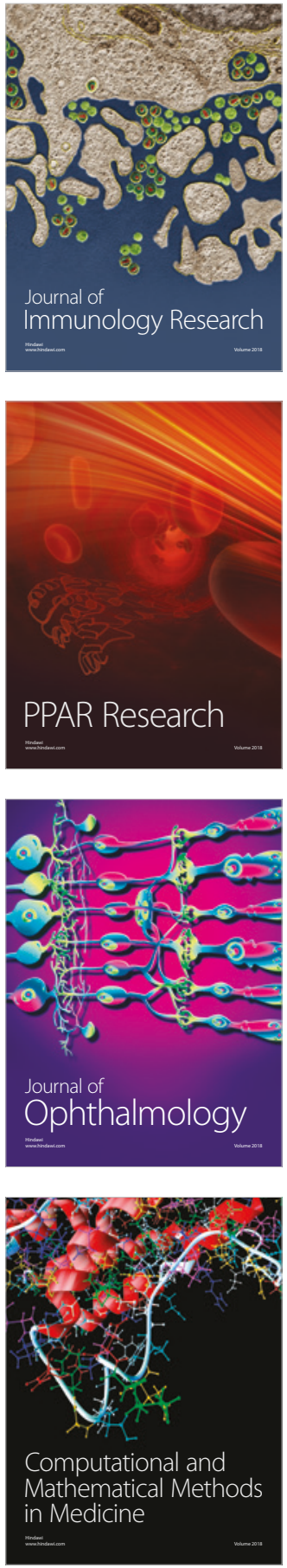

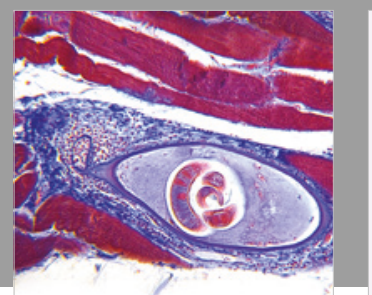

Gastroenterology Research and Practice

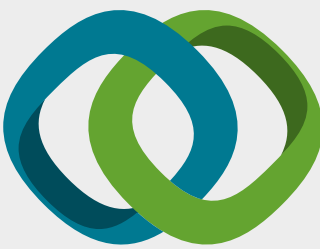

\section{Hindawi}

Submit your manuscripts at

www.hindawi.com
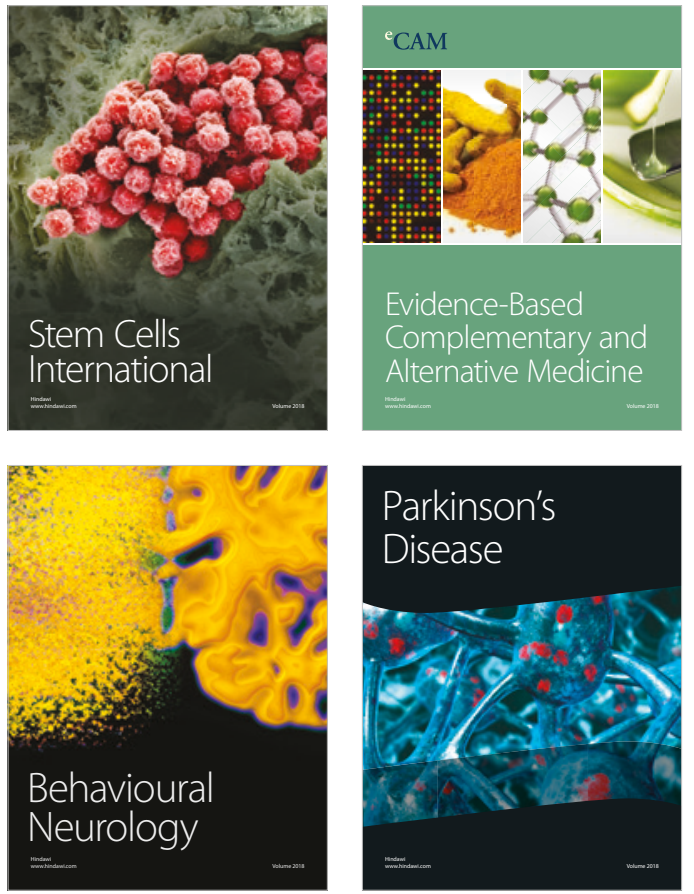

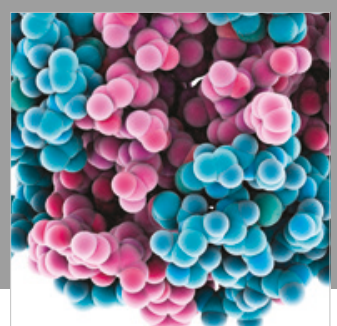

ournal of

Diabetes Research

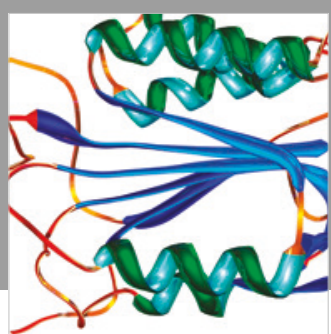

Disease Markers
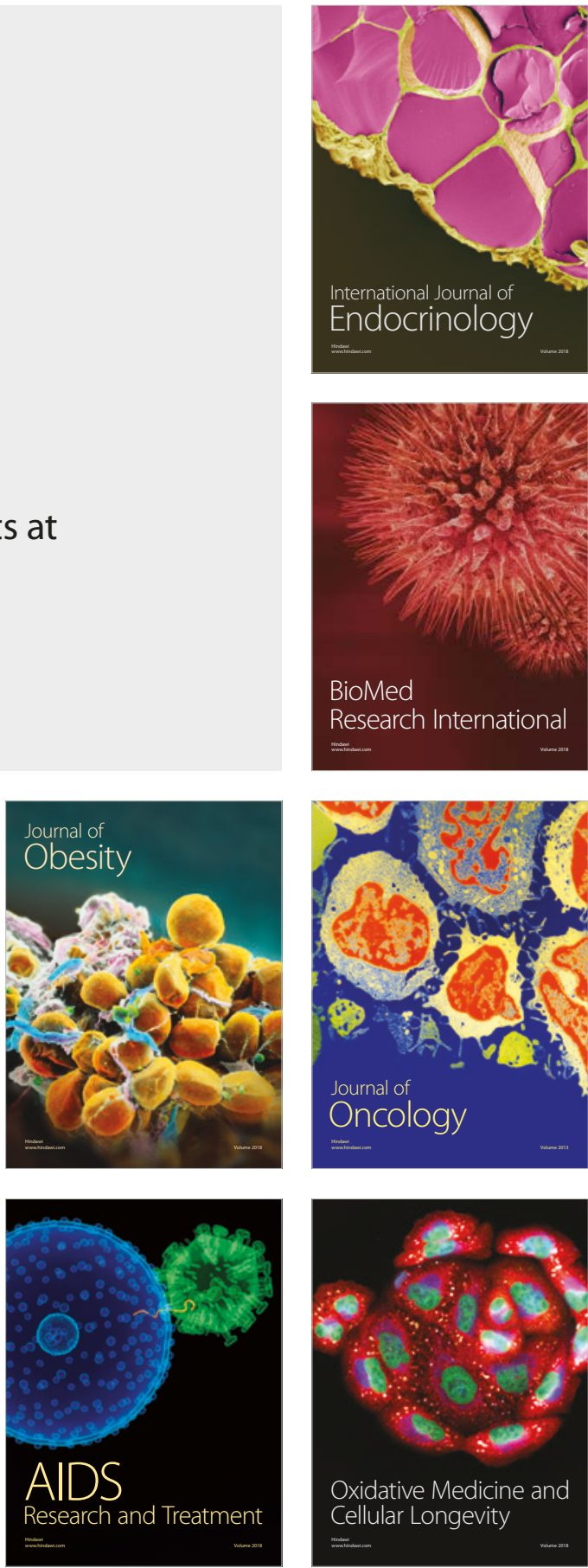